\title{
Giant Lipoma in the Fronto-Temporo-Parietal Region in an Adult Man: Case Report and Literature Review
}

This article was published in the following Dove Press journal: Clinical, Cosmetic and Investigational Dermatology

\author{
Monika Szewc $\mathbb{D}^{1, *}$ \\ Piotr Gawlik (D) ${ }^{2, *}$ \\ Remigiusz Żebrowski ${ }^{2}$ \\ Robert Sitarz $\mathbb{D}^{1,2}$ \\ 'Department of Normal Anatomy, \\ Medical University of Lublin, Lublin, \\ Poland; ${ }^{2}$ Department of Surgery, \\ St. John's Cancer Center, Lublin, Poland \\ *These authors contributed equally to \\ this work
}

\begin{abstract}
Lipoma belongs to a group of benign mesenchymal tumors. It is in the form of soft masses of adipose tissue encapsulated by a thin layer of fibrous tissue and usually localized subcutaneously. The tumor most often appears in the upper part of the body. Lipomas tend to grow slowly and are small (less than $5 \mathrm{~cm}$ ) lesions. Larger tumors are rare. In this article, we present the case of a patient with a giant head lipoma in the frontotemporo-parietal region. Both tumor size and location are unique and no such case has been described in the literature so far.
\end{abstract}

Keywords: giant head lipoma, benign tumor

\section{Introduction}

Lipomas belong to a group of mesenchymal tumors. Most often they create benign changes in the form of soft, movable masses of mature adipose cells having a minimal connective tissue stroma. They are commonly encapsulated by a thin layer of fibrous tissue and typically localized subcutaneously. Lipomas most often occur individually. Multiple lipomas affect only 5\% of all cases.

These changes are often presented in the upper part of the body, especially in the head, neck, shoulders and back. ${ }^{1}$ In rare cases, lipomas may appear in the other regions of the human body or even in internal organs such as heart or stomach. ${ }^{2-4}$ Usually the resulting lesions are harmless and painless, therefore do not require treatment. However, if lipomas encroach on joints, nerves or blood vessels, their removal may be necessary. Patients may also choose treatment for aesthetic reasons.

The frequency of lipomas in the population is estimated at $1 \%$. In the majority of cases, they are diagnosed between the age of 40 and 60. The disease affects women and men equally. Lipomas tend to grow slowly and mostly their width is less than $5 \mathrm{~cm}$. Rapid growing and larger lesions are rare. ${ }^{1}$

Cases of head and neck lipoma constitute $13 \%$ of all diagnosed lipomas. ${ }^{5}$ In this article, we present the case of a patient with a giant head lipoma.

\section{Case Report}

A 66-year-old man was admitted to the clinic with a large protuberance in the head area. The patient underwent clinical examination and computed tomography. An imaging test showed a lesion with the features of a lipoma measuring $9 \mathrm{~cm} \mathrm{x} 3 \mathrm{~cm}$
Department of Normal Anatomy, Medical University of Lublin, Jaczewskiego Str. 4,

20-09I, Lublin, Poland

Tel +48 8I 454 II3।

$\mathrm{Fax}+48815322395$

Email r.sitarz@umlub.pl 
$\mathrm{x} 10.5 \mathrm{~cm}$ and located in the subcutaneous tissue of the frontal area. The CT scan showed no signs of bone resorption or infiltration of the periosteum. In an interview, the man reported that this lesion was developing for several years. The patient had no significant past medical history.

The man was diagnosed with a lipoma subcutaneous tissue lesion in the fronto-temporo-parietal region (Figure 1). It was decided to undergo surgery. Under general anesthesia, the skin incision triangles formed three star-like points (Figure 2). The tumor was mainly located in the subcutaneous layer, however, deep extensions were seen reaching epicranial aponeurosis. Mobilization of the skin was not necessary, excess skin has been cut. Finally, the skin was closed with nonabsorbable sutures - closing the flaps and resulting in the classic Mercedes star shape (Figure 3). ${ }^{6}$

The operation went without any complications. Pathological examination of the specimen confirmed the diagnosis of lipoma. Due to the size and nature of the tumor molecular analysis was performed. Lack fluorescence in-situ hybridization (FISH) for MDM2 amplification confirmed the diagnosis of benign lipoma (Figure 4).

The man left the clinic alone, in generally satisfactory condition. He was recommended a 14-day sparing lifestyle, followed by gradual physical rehabilitation. A follow-up visit was also set.
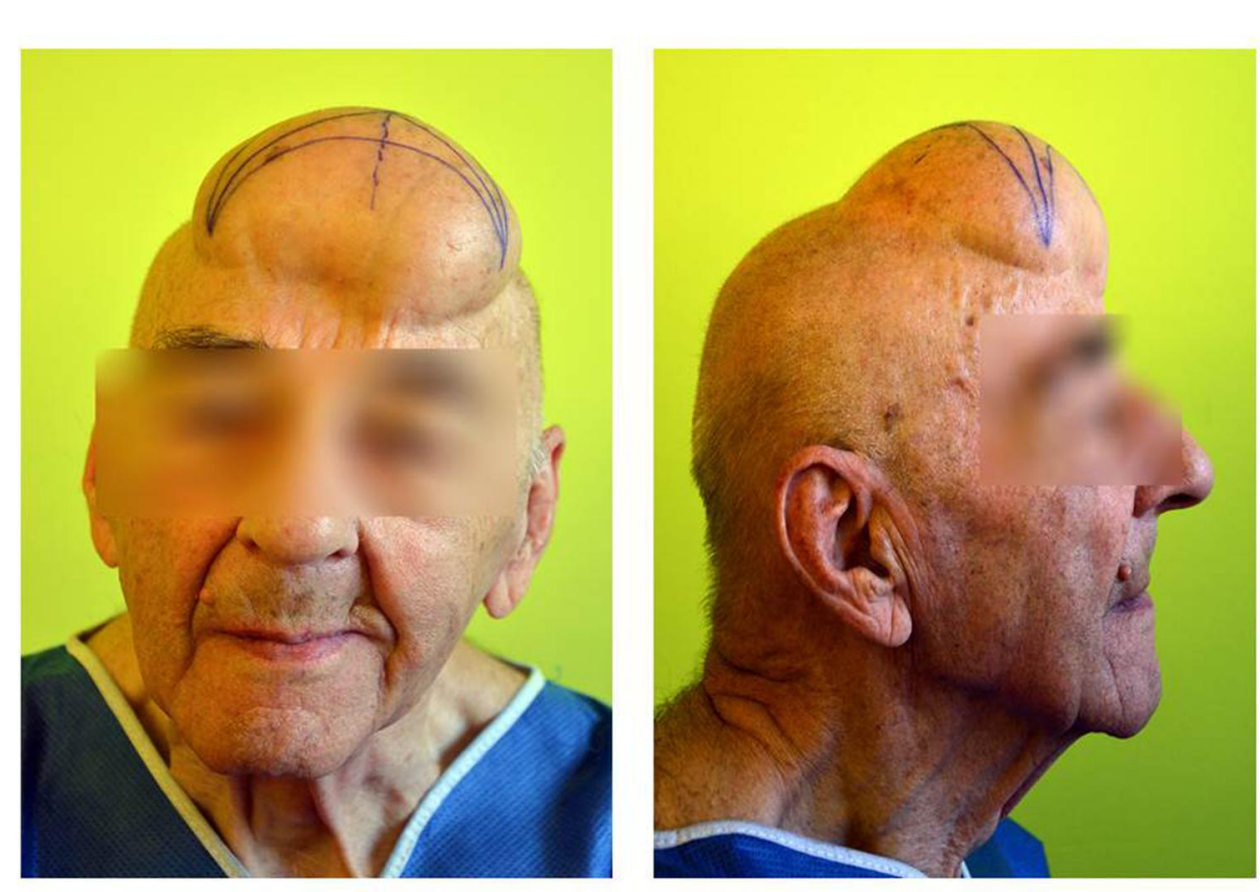

Figure I Giant lipoma of the head - patient before surgery.

\section{Discussion}

The etiology and pathogenesis of lipomas are still unknown. In addition, the mechanism of rapid growth into giant lipomas is unclear and is still under discussion. There are few studies suggesting that blunt trauma can lead to rapid proliferation of adipose tissue as a result of rupture of the fibrous septa and anchorage connections between the skin and deep facia. ${ }^{7}$ It has also been proposed that local inflammation secondary to trauma may be the reason for preadipocytes differentiation and maturation. ${ }^{7,8}$ Furthermore, the occurrence of benign lipomatous lesions may be associated with other disorders such as Dercum's disease and Madelung's disease., ${ }^{9,10}$ Among the potential risk factors that may be the cause of lipomas, there are: obesity, alcohol abuse, liver disease and glucose intolerance. ${ }^{1}$

Giant lipomas are rarely diagnosed. There are few case reports in the literature describing the presence of such changes in various areas of the human body. Sanchez et $\mathrm{al}^{11}$ defined giant lipoma as a lesion larger than $10 \mathrm{~cm}$ in diameter in one dimension or weighing over 1000 g. These tumors usually occur in the head, neck, shoulders, abdomen or extremities. Consequently, it may cause a deterioration in the quality of life. The localization of fat masses can limit body functions and movements. Depression disorders are often another implication of the disease. Therefore, the painfulness of changes, limitation 

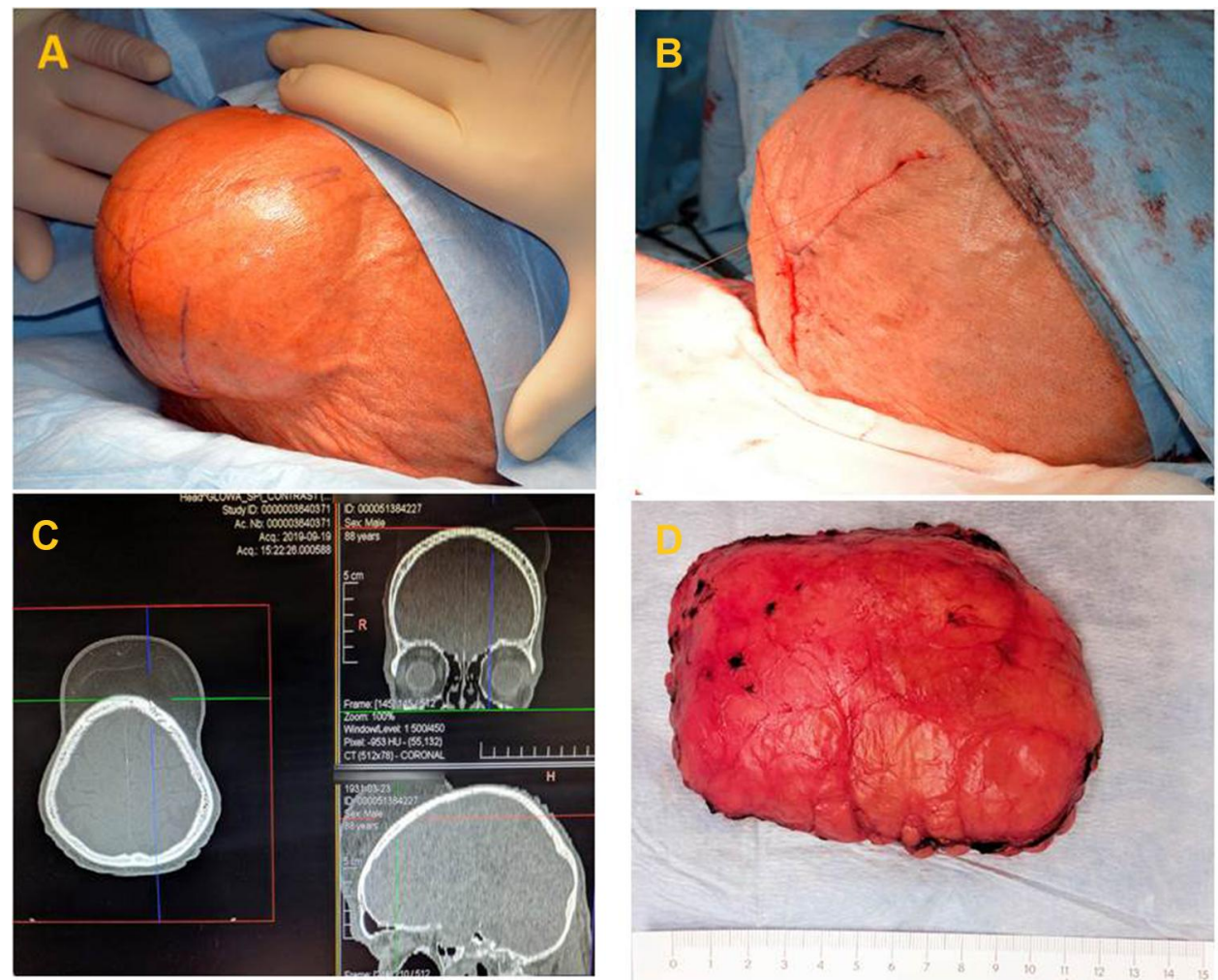

Figure 2 Giant lipoma of the head: preoperative appearance (A); Mercedes star-shaped skin closure (B); CT scan (C); operative specimen (D).

of organ function, discomfort and difficulties in accepting own appearance are the main reasons for starting treatment. $^{12}$

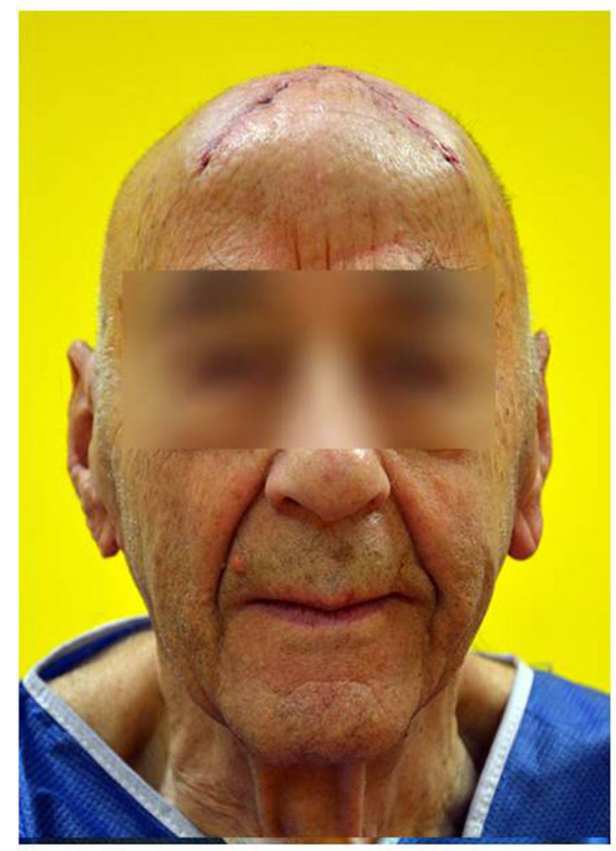

Diagnosis of head lipomas is based on clinical examination and imaging tests, such as computed tomography or magnetic resonance imaging. Both tests allow for the correct

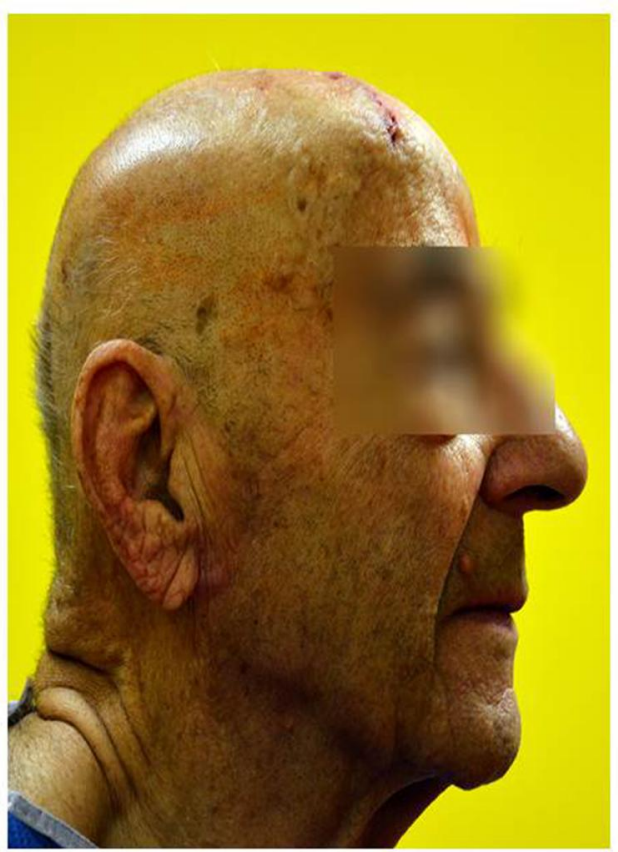

Figure 3 Patient after surgery. 

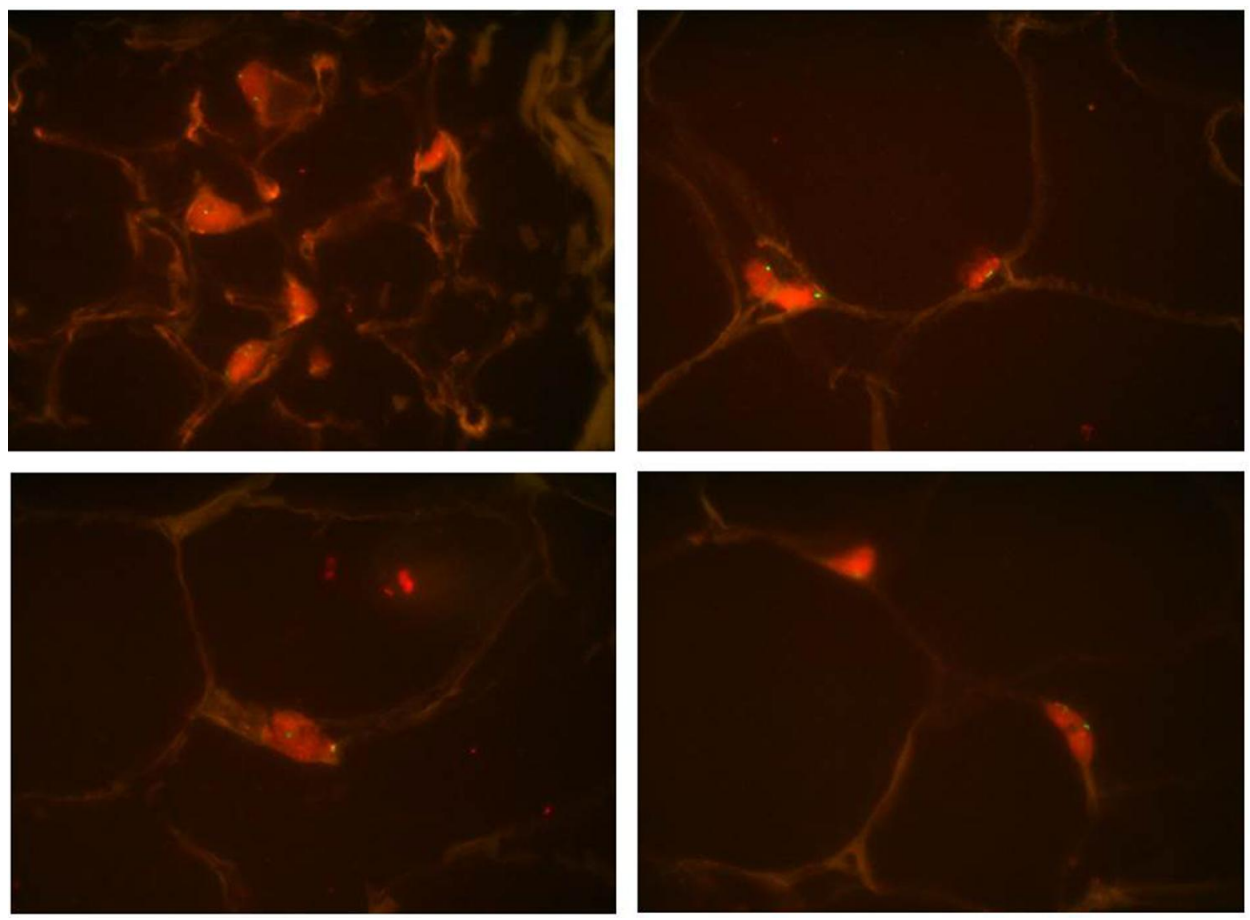

Figure 4 Lipoma with a negative MDM2/CEPI2 FISH assay (MDM2-red signals and CEPI2-green signals).

diagnosis of lipoma preoperatively, thanks to which treatment can be properly planned. ${ }^{5}$ Ultrasonography and fine needle aspiration can be also useful investigations to determine the nature of a lipomatous lesion. ${ }^{5,13}$ However, lipoma and liposarcoma differentiation can be carried out with certainty only by a careful histopathological examination of the operative specimen. ${ }^{5}$ To discriminate lipoma from atypical lipomatous tumor/well-differentiated liposarcoma (ALT/ WDL) additional analysis should be performed. MDM2 (Murine Double Minute clone 2) amplification by fluorescence in-situ hybridization is a highly sensitive and a specific marker for the diagnosis of ALT/WDL. It is highly justified in the following situations: lipomatous tumors with borderline cytologic atypia, recurrent lipomas, large lipomas and retroperitoneal/intra-abdominal lipomatous tumors without atypia.

The implementation of surgical treatment of a giant lipoma is justified. It aims to relieve symptoms and to limit the possibility of further enlargement of the lesion. ${ }^{14}$ Surgical excision through incisions made in the skin overlying the tumor is currently the treatment of choice for larger lipomas. ${ }^{15}$ Such an approach is a relatively straightforward method that allows complete removal of the tumor, considering the encapsulated nature of the lipoma. After the complete excision of the lesion, the risk of local recurrence is less than $5 \%{ }^{16}$

Other methods used to remove lipomatous changes are liposuction, endoscopic removal and laser extirpation. ${ }^{17-19}$ Liposuction is a technique rarely used in the treatment of giant lipomas. It is considered that the removal may be incomplete and the risk of recurrence is higher than after conventional excision. However, numerous reports show that liposuction or combined liposuction and excision are also successful methods of removal of such lesions. ${ }^{20,21}$ Liposuction as well as endoscopic removal and laser lipolysis are also evaluated as giving an excellent cosmetic effect in giant lipoma treatment. ${ }^{22,23}$

In this case report, we describe a patient who has undergone resection of a giant head lipoma using a standard surgical approach. It was a solitary tumor in an elderly man. This lesion was located in the fronto-temporo-parietal region and was in the form of a cosmetically unacceptable protuberance. This was a source of discomfort for the patient in everyday life. Clinical examination and a computed tomography scan confirmed the presence of a benign lipomatous tumor. The implementation of surgical treatment was necessary for aesthetic concerns and to improve the patient's quality of life. The operation was performed with success 
and without any complications. Pathological final examination confirmed the diagnosis of the tumor as lipoma. To the best of our knowledge, there have been no previous reports in the literature of an exciting giant head lipoma located in the fronto-temporo-parietal region.

\section{Conclusions}

Giant lipomas on the head are a rare condition, preferably treated by surgical excision. This therapeutic approach avoids damage caused by tumor compression to other structures and provides better control against local recurrences. Preoperative imaging is important in planning the extent of surgery.

The described patient had a giant lipoma in an infrequent location for lipomatous tumors. Such a large and single lesion in the fronto-temporo-parietal region has not been reported so far. This case is proof that a giant lipoma in the head area can be successfully removed by surgical treatment. In addition, the cosmetic and functional results of the surgery can be satisfactory for the patient and his quality of life can also be improved.

\section{Patient Consent}

The authors certify that they have obtained all appropriate patient consent forms. Patient gave written consent for publication clinical information and photographs. Institutional approval is not required for this case study.

\section{Acknowledgment}

The authors would like to thank Prof. Janusz Ryś (Department of Tumour Pathology, Institute of Oncology, Krakow, Poland) for performing FISH for MDM2 gene analysis.

\section{Disclosure}

The authors report no conflicts of interest for this work.

\section{References}

1. Charifa A, Badri T. Lipomas, Pathology. StatPearls Publishing; 2018.

2. Singh V, Kumar V, Singh AK. Case report: a rare presentation of giant palmar lipoma. Int J Surg Case Rep. 2016;26:21-23. doi:10.1016/j. ijscr.2016.06.036

3. Wang X, Yu X, Ren W, Li D. A case report: a giant cardiac atypical lipoma associated with pericardium and right atrium. BMC Cardiovasc Disord. 2019;19(1):247. doi:10.1186/s12872-019-1221-1

4. Amundson JR, Straus D, Azab B, Liu S, Garcia Buitrago MT, Yakoub D. Giant symptomatic gastric lipoma: a case report and literature review. Int J Surg Case Rep. 2018;51:313-317. doi:10.1016/j. ijscr.2018.08.061
5. El-Monem MHA, Gaafar AH, Magdy EA. Lipomas of the head and neck: presentation variability and diagnostics work-up. $J$ Laryngol Otol. 2006;120(1):47-55. doi:10.1017/S0022215105004597

6. Tamir G, Birkby CS, Berg D. Three point-advancement closure for skin defects. J Cutan Med Surg. 1999;3(6):288-292. doi:10.1177/ 120347549900300602

7. Signorini M, Campiglio GL. Posttraumatic lipomas: where do they really come from? Plast Reconstr Surg. 1998;101(3):699-705. doi:10.1097/00006534-199803000-00017

8. Copcu E, Sivrioglu NS. Posttraumatic lipoma: analysis of 10 cases and explanation of possible mechanisms. Dermatol Surg. 2003;29 (3):215-220.

9. Kucharz EJ, Kopeć-Mędrek M, Kramza J, Chrzanowska M, Kotyla P. Dercum's disease (adiposis dolorosa): a review of clinical presentation and management. Reumatologia. 2019;57(5):281-287. doi:10.5114/reum.2019.89521

10. Szewc M, Sitarz R, Moroz N, Maciejewski R, Wierzbicki R. Madelung's disease - progressive, excessive, and symmetrical deposition of adipose tissue in the subcutaneous layer: case report and literature review. Diabetes Metab Syndr Obes. 2018;26 (11):819-825. doi:10.2147/DMSO.S181154

11. Sanchez MR, Golomb FM, Moy JA, Potozkin JR. Giant lipoma: case report and review of the literature. J Am Acad Dermatol. 1993;28 (2):266-268. doi:10.1016/S0190-9622(08)81151-6

12. Guler O, Mutlu S, Mahirogulları M. Giant lipoma of the back affecting quality of life. Ann Med Surg. 2015;4(3):279-282. doi:10.1016/j.amsu.2015.08.001

13. Singh M, Saxena A, Kumar L, Karande SK, Kolhe Y. Giant lipoma of posterior cervical region. Case Rep Surg. 2014;2014:289383.

14. Zaroo MI, Bashir SA, Mohsin M, Baba PUF, Farooq SSA, Zargar HR. Giant lipoma: a case report. J IMA. 2011;43(2):77-79.

15. Salam GA. Lipoma excision. Am Fam Physician. 2002;65 (5):901-904.

16. Goldblum JR, Folpe AL, Weiss SW. Enzingerand Weiss's Soft Tissue Tumors. 7th ed. Elsevier; 2019.

17. Hallock GG. Endoscope-assisted suction extraction of lipomas. Ann Plast Surg. 1995;34(1):32-34. doi:10.1097/00000637-19950100000007

18. Spinowitz AL. Liposuction surgery: an effective alternative for treatment of lipomas. Plast Reconstr Surg. 1990;86(3):606. doi:10.1097/ 00006534-199009000-00059

19. Lee SH, Jung JY, Roh MR, Chung KY. Treatment of lipomas using a subdermal 1, 444-nm micropulsed neodymium- doped yttrium aluminum garnet laser. Dermatol Surg. 2011;37(9):1375-1376.

20. Copeland-Halperin LR, Pimpinella V, Copeland M. Combined liposuction and excision of lipomas: long-term evaluation of a large sample of patients. Plast Surg Int. 2015;2015:625396.

21. Choi CW, Kim BJ, Moon SE, Youn SW, Park KC, Huh CH. Treatment of lipomas assisted with tumescent liposuction. $J$ Eur Acad Dermatol Venereol. 2007;21(2):243-246. doi:10.1111/j.14683083.2006.02037.x

22. Gverić T, Huljev D, Zdilar B, et al. Endoscopically assisted lipectomy. Acta Med Croatica. 2010;64(3):205-208.

23. Stebbins WG, Hanke CW, Petersen J. Novel method of minimally invasive removal of large lipoma after laser lipolysis with $980 \mathrm{~nm}$ diode laser. Dermatol Ther. 2011;24(1):125-130. doi:10.1111/j.15298019.2010.01385.x 


\section{Publish your work in this journal}

Clinical, Cosmetic and Investigational Dermatology is an international, peer-reviewed, open access, online journal that focuses on the latest clinical and experimental research in all aspects of skin disease and cosmetic interventions. This journal is indexed on CAS.
The manuscript management system is completely online and includes a very quick and fair peer-review system, which is all easy to use. Visit http://www.dovepress.com/testimonials.php to read real quotes from published authors.

Submit your manuscript here: https://www.dovepress.com/clinical-cosmetic-and-investigational-dermatology-journal 